\title{
Quantifying parameters of the seat-occupant interface during simulated low speed rear-impact collisions
}

Jackie D. Zehr

Department of Kinesiology,

University of Waterloo,

Waterloo, ON, Canada, N2L 3G1

Email: jackie.zehr@uwaterloo.ca

\section{Kayla M. Fewster}

Human Health and Nutritional Sciences,

University of Guelph,

Guelph, ON, Canada, N1G 2W1

Email: kfewster@uoguelph.ca

\section{David C. Kingston}

College of Education, Health, and Human Sciences,

University of Nebraska Omaha,

Omaha, NE, 68182, USA

Email: dkingston@unomaha.edu

\section{Chad E. Gooyers and Robert J. Parkinson}

Department of Kinesiology,

University of Waterloo,

Waterloo, ON, Canada, N2L 3G1

and

Biomechanics Group,

30 Forensic Engineering,

Toronto, ON, Canada

Email: cgooyers@30fe.com

Email: rparkinson@30fe.com

\section{Jack P. Callaghan*}

Department of Kinesiology,

University of Waterloo,

Waterloo, ON, Canada, N2L 3G1

Fax: 519-746-6776

Email: jack.callaghan@uwaterloo.ca

${ }^{*}$ Corresponding author 
Abstract: The influence of supplemental lumbar support on automobile seat surface pressures was measured during simulated rear impact collisions with human volunteers. Men and women $($ age $=25.4 \pm 3.4$ years; $B M I=25.2 \pm 3.9$; stature $=1.73 \pm 0.06 \mathrm{~m}$ ) experienced two low-velocity rear impact collisions. Simulated collisions with and without a lumbar support were conducted in random sequence. Using a pressure sensing mat that contained 2288 ferroresistive sensors, seatback pressure was recorded at a rate of $500 \mathrm{~Hz}$. These data were used to compute the total seatback force, area of force concentration, and centre-of-force $(\mathrm{CoF})$. Total seatback force was not significantly different from body mass for either men or women $(\approx 1.2 \times$ body mass). Average contact area of the occupant's back with the seatback (i.e., area of force concentration) was approximately $221.3 \mathrm{~cm}^{2}$ and $100.1 \mathrm{~cm}^{2}$ greater without supplemental lumbar support for men and women, respectively. With respect to the $L_{4}$ spinal level, the $\mathrm{CoF}$ had a greater vertical distance without lumbar support and a greater horizontal distance with lumbar support. In conclusion, the lumbar support used in this study altered the location and distribution of seatback forces applied to the occupant's back.

Keywords: lumbar support; rear impact; accidents; low-back injuries; pressure; lumbar spine; traffic accident; seatback force.

Reference to this paper should be made as follows: Zehr, J.D., Fewster, K.M., Kingston, D.C., Gooyers, C.E., Parkinson, R.J. and Callaghan, J.P. (2021) 'Quantifying parameters of the seat-occupant interface during simulated low speed rear-impact collisions', Int. J. Vehicle Design, Vol. 85, No. 1, pp.32-47.

Biographical notes: Jackie D. Zehr is a PhD Candidate at the University of Waterloo. Jackie has previously completed a Bachelor of Kinesiology (2015) and MSc (2017), both at the University of Toronto. The overarching aim of her doctoral research program is to understand the fundamental processes of damage and fatigue-failure in lumbar spine tissues. She hopes to apply these basic science findings to improve load management practice in training, occupational, and rehabilitation settings.

Kayla M. Fewster is currently a Postdoctoral fellow at the University of Guelph in the department of Human Health and Nutritional Sciences. Overall, her research interests focus on relating temporal mechanical changes in the lumbar spine to changes in motor control responses and intervertebral joint mechanics in response to sudden impacts, perturbations and acute loading scenarios. Her area of research aims to uncover the role of exposure history, situational variables (such as aging, obesity and sex) and post impact responses in injury initiation and progression following high-rate loading scenarios.

David. C. Kingston is an Assistant Professor in the Department of Biomechanics at the University of Nebraska Omaha. He is Co-Director of UNO's Movement Analysis Core, a service core that provides internal and external clients with access to research capacity in addition to maintaining our department's world class facilities. A primary research focus is using biomechanical techniques to improve rehabilitation and surgical outcomes in children with cerebral palsy. He held a post-doctoral position at the University of Saskatchewan's College of Medicine, completed his $\mathrm{PhD}$ at Waterloo in Kinesiology, and has an MSc and BSc from Queen's University.

Chad E. Gooyers is the Regional Director for Western Canada at 30 Forensic Engineering, specialising in the biomechanical assessment of injury causation. 
He has been published in top biomechanics journals and holds academic appointments at leading Canadian Universities. He consults with legal and insurance clients across Canada and the US; he has been qualified in the Ontario Superior of Justice to give Expert Evidence in biomechanics, injury mechanisms, occupant motion and seatbelt and airbag use/effectiveness.

Robert J. Parkinson is an Injury Biomechanics specialist, and the Vice President \& Practice Lead of the Biomechanics and Personal Injury Assessment group at 30 Forensic Engineering. During his time in the forensics industry, he has investigated claims involving motor vehicle collisions, slips, trips and falls, seatbelt and helmet use, product failure, and work-related claims. He holds an adjunct faculty position at the University of Waterloo and remains active in the teaching and research community.

Jack P. Callaghan is a Professor in the Department of Kinesiology and the Canada Research Chair in Spine Biomechanics and Injury Prevention. His research program combines a fundamental in-vitro research approach, examining the time varying response of the lumbar spine tissues, with in-vivo human research, examining biological responses to cumulative loading exposure from both pain generating and tissue altering/injuring perspectives.

This paper is a revised and expanded version of a paper entitled 'Quantifying the seat-occupant interface during low-velocity rear impact collisions' presented at 20th Biennial Meeting of the Canadian Society for Biomechanics, Halifax, Nova Scotia, Canada, 14-17 August, 2018.

\section{Introduction}

The reporting of acute (Brison et al., 2000) and chronic (Berglund et al., 2001) low back pain is a significant cause of physical disability following rear impact motor vehicle collisions (MVC). Approximately 50\% of individuals involved in low-severity rearimpact collisions-characterised by minimal vehicular damage and/or a low magnitude of velocity change-will seek medical treatment for complaints of low back pain (Fast et al., 2002, Gushue et al., 2006). In addition to the personal costs associated with rear-impact related low back disorders (e.g., pain, emotional distress), the economic burden associated with lifetime compensation costs and lost work years is approximately $\$ 58.7$ billion in US (Seifert, 2007). Accordingly, there is considerable motivation to investigate the possible factors influencing low back pain and injury generation during low-velocity rear impact collisions.

One proposed mechanism of low-back pain development following a rear impact MVC is excessive lumbar facet-joint capsule strain, which is believed to initiate a neurophysiological cascade that ultimately increases nociceptor sensitivity (Cavanaugh et al., 2006). The facet joints play an important role in transmitting forces through the spinal column, particularly when there is anterior-posterior shear displacement of adjacent vertebrae (Yingling and McGill, 1999). The capacity of the lumbar facet joints to withstand and transmit anterior shear force during a rear impact collision may be altered by spinal posture (Howarth and Callaghan, 2012, Gallagher et al., 2005, Drake et al., 2005) and concurrent compressive loading applied (Howarth and Callaghan, 2012). Since post-collision medical imaging performed on the low back does not typically reveal any 
lesions or tissue damage, diagnoses and severity of low back injuries said to result from MVCs are typically based on subjective pain reports. Thus, objective biomechanical analyses of the internal joint loading response, including high fidelity seatback force estimates during low-velocity rear impact collisions is necessary to advance the identification and understanding of possible mechanisms responsible for pain reporting.

Common approaches to study lumbar spine loading during rear impact collisions include instrumenting the spinal tissues of post mortem human subjects (PMHS) (Fast et al., 2002) or via anthropomorphic test devices (ATDs) instrumented with load transducers at the lumbosacral junction (Gushue et al., 2006, Gates et al., 2010). Alternatively, it is feasible to examine the loading response in vivo during simulated lowvelocity collisions using biologically-assisted musculoskeletal models of the lumbar spine (McGill and Norman, 1986, van Dieën and de Looze, 1999). This approach requires the accurate acquisition of all internal (i.e., spinal posture, muscular activation) and external (i.e., seatback force) parameters and may be more sensitive and insightful to muscular tone and bracing prior to the impact. One problem, however, is that a standard and accurate method for determining seatback reaction forces has not been devised. Fast et al. (2002) measured seatback forces by longitudinally embedding three biaxial load cells on the sagittal mid-line of the seatback, while Lawrence and Siegmund (2000) estimated force from measurements of seatback deformation quantified via linear potentiometers. Effectively, the first sensor arrangement only quantifies the reaction force applied to the focal area of the transducer-sensing surface(s) and the second approach assumes all deformation is due to seat-occupant contact and is highly dependent on stiffness properties of the seating materials. Furthermore, the precise point of force application from the seat back on the occupant cannot be accurately determined using either approach, which is necessary for inverse dynamic analyses aimed at understanding the internal loading response (Winter, 2009).

Although it may be necessary to use ATDs and/or PMHS to examine mechanical loading during higher severity crash simulations, these methods may not offer the biological sensitivity required to investigate injury potential and symptom reporting during and after low-to-moderate velocity rear impact MVCs. Further, the instrumentation methods employed by Fast et al. (2002) and Lawrence and Siegmund (2000) do not immediately consider the seatback characteristics (i.e., lumbar support) or the potential influence of design features (e.g., bilateral seat bolsters) that may be captured if alternative sensing systems and post-processing analyses were implemented. For example, radiographic evidence has shown that the use of lumbar support prominences during simulated driving can alter low back posture (De Carvalho and Callaghan, 2012) and reduce discomfort while driving (Chen et al., 2005, Donnelly et al., 2009). Despite these ergonomically justified benefits, however, lumbar supports also change the seatback contour and the potential of this altered geometry to influence pressure distribution and force transferred from the seatback to the occupant during rear impact collisions has not been evaluated and is unlikely to be captured with previously employed seatback instrumentation approaches (Fast et al., 2002; Lawrence and Siegmund, 2000).

To address these knowledge gaps, the primary purpose of this investigation was to examine the influence of mechanical lumbar support on characteristics of the seatoccupant interface during laboratory-simulated low-velocity rear impact MVCs. The seatoccupant interface was characterised by quantifying the total seatback force, the area of contact between the seat back and the occupant's back, the and centre-of-force ( $\mathrm{CoF})$ 
location with respect to the lumbar spine from pressure-time data that was recorded during each simulated MVC. A secondary study objective was to devise and apply a method for quantification of total seatback force magnitude, force concentration area, and point of force application during simulated rear-impact collisions using a pressure measurement system.

\section{Methods}

\subsection{Participants}

Twenty-two individuals (11 men and 11 women) without a self-reported history of physician diagnosed mild traumatic brain injury (e.g., concussion), cervical spine whiplash, and low-back or pelvis disorders were recruited from a university sample of convenience. Participants were eligible if they had body mass and stature that were between the 10th and 90th percentile quantities of their reported biological sex (Table 1). The summary statistics of the evaluated sample are reported in Table 1. At the time of participation, $50 \%$ of participants were classified as healthy based on their body mass index (BMI) $(18 \leq \mathrm{BMI} \geq 24)$, while $41 \%$ and $9 \%$ were considered to have been overweight $(29 \leq \mathrm{BMI} \geq 25)$ and obese $(40 \leq \mathrm{BMI} \geq 30)$, respectively. In comparison to the prevalence of adult obesity in US $(\approx 34 \%)$ (Flegal et al., 2016, Hales et al., 2018) and Canada $(\approx 25 \%)$ (Bancej et al., 2015), the population examined in this study had a considerably better health status and a smaller body size compared to the average age-matched North American person. Prior to data collection, all participants were provided an opportunity to watch a video of the simulated collision that included a 50th percentile male Hybrid III ATD and if still interested, provided written informed consent. The University of Waterloo's Office of Research Ethics approved all procedures and documentation used in this study.

\subsection{Experimental approach}

Participants were exposed to two laboratory-simulated rear impact MVCs completed during separate test sessions spaced a minimum of 14 days apart. The collision tests were conducted on a custom-built sled-track unit that replicated a previously used design concept (Kaneoka et al., 1999) (Figure 1). The test sled was composed of a Honda CRV automobile seat from the driver's position (2017 Model obtained from Schukra of North America Canada: $10 \mathrm{~cm}$ bilateral trim; $50 \mathrm{~cm}$ seat pan; $30 \mathrm{~cm}$ seatback (not including the trim); vertically adjustable head restraint) reclined to an angle of $27^{\circ}$ (Siegmund et al., 2001), with an adjustable foot platform to facilitate an inter-participant knee angle of approximately $110^{\circ}$ (Arbogast et al., 2012). The $27^{\circ}$ angle of recline represented the angle between the seatback and a plane originating from the recline pivot point that was perpendicular to the seat pan. The seating platform accelerated down a $1.4 \mathrm{~m}$ plane that had an inclination angle of $5.8^{\circ}$ for an approximate duration of 1.65 seconds until it simultaneously struck four custom springs (Omnicoil, Ayr, ON) with stiffness and damping parameters that were tuned to $31,991 \mathrm{~N} / \mathrm{m}$ and $593.78 \mathrm{Ns} / \mathrm{m}$, respectively (Barrett et al., 2018). These spring parameters were optimised to facilitate the desired impact parameters that were a reflection of the impulse reported by Siegmund et al. (2000). The total mass of the seating platform was standardised to $113.4 \mathrm{~kg}$ by fastening additional mass (i.e., the difference between the participant's body mass and $113.4 \mathrm{~kg}$ ) to 
its base. This ensured a collision-induced change in velocity $(\Delta \mathrm{V})$ of approximately $8 \mathrm{~km} / \mathrm{h}$ for participants of varying body mass when released from the same track location. Given that motorists often report "not seeing the collision coming" during their reported traffic accident (Brison et al., 2000), participants were blindfolded and wore headphones during the simulated crash in attempt to minimise anticipation of the impending impact and to enhance the fidelity of the simulated scenario. Prior to each collision, all participants were instructed to do the following:

1 position their arms at their sides with their hands placed in their lap

2 sit with their trunk in an erect and forward-facing position while ensuring that their back was against the seatback

3 look in the forward direction as if they were driving.

Table 1 Summary of participant anthropometrics

\begin{tabular}{|c|c|c|c|c|c|c|}
\hline $\begin{array}{l}\text { Participant } \\
\text { (no.) }\end{array}$ & $\begin{array}{c}\text { Sex } \\
(M / F)\end{array}$ & $\begin{array}{c}\text { Age } \\
\text { (years) }\end{array}$ & $\begin{array}{c}\text { Stature } \\
\text { (m) }\end{array}$ & $\begin{array}{l}\text { Body mass } \\
(\mathrm{kg})\end{array}$ & $\begin{array}{c}B M I \\
\left(\mathrm{~kg} / \mathrm{m}^{2}\right)\end{array}$ & $\begin{array}{l}\text { Waist width } \\
(\mathrm{cm})\end{array}$ \\
\hline 1 & $\mathrm{M}$ & 29 & 1.78 & 92.9 & 29.3 & 34.1 \\
\hline 2 & M & 23 & 1.76 & 84.3 & 27.2 & 33.8 \\
\hline 3 & $\mathrm{~F}$ & 22 & 1.72 & 68.4 & 23.1 & 29.2 \\
\hline 4 & F & 30 & 1.75 & 85.2 & 27.8 & 32.2 \\
\hline 5 & F & 30 & 1.66 & 75.7 & 27.4 & 32.9 \\
\hline 6 & M & 25 & 1.71 & 82.7 & 28.2 & 32.6 \\
\hline 7 & $\mathrm{M}$ & 27 & 1.69 & 77.4 & 27.1 & 32.8 \\
\hline 8 & $\mathrm{M}$ & 23 & 1.82 & 66.7 & 20.1 & 29.1 \\
\hline 9 & F & 26 & 1.66 & 60.8 & 22.1 & 28.3 \\
\hline 10 & $\mathrm{~F}$ & 19 & 1.62 & 55.8 & 21.3 & 26.8 \\
\hline 11 & $\mathrm{~F}$ & 22 & 1.72 & 84.7 & 28.6 & 30.1 \\
\hline 12 & M & 32 & 1.74 & 96.2 & 31.8 & 36.5 \\
\hline 13 & $\mathrm{M}$ & 30 & 1.80 & 95.2 & 29.4 & 33.9 \\
\hline 14 & $\mathrm{~F}$ & 26 & 1.73 & 57.6 & 19.2 & 27.6 \\
\hline 15 & M & 31 & 1.82 & 68.0 & 20.5 & 31.2 \\
\hline 16 & F & 28 & 1.63 & 80.4 & 30.3 & 31.9 \\
\hline 17 & $\mathrm{~F}$ & 22 & 1.71 & 58.9 & 20.1 & 28.1 \\
\hline 18 & $\mathrm{~F}$ & 23 & 1.72 & 71.2 & 24.1 & 29.6 \\
\hline 19 & M & 22 & 1.80 & 67.8 & 20.9 & 32.4 \\
\hline 20 & M & 26 & 1.75 & 90.7 & 29.6 & 34.1 \\
\hline 21 & M & 22 & 1.78 & 69.4 & 21.9 & 33.0 \\
\hline 22 & $\mathrm{~F}$ & 21 & 1.66 & 66.7 & 24.2 & 28.7 \\
\hline Mean & & 25.4 & 1.73 & 75.3 & 25.2 & 31.3 \\
\hline SD & & 3.7 & 0.06 & 12.2 & 3.9 & 2.6 \\
\hline
\end{tabular}


In a randomised order, the collisions were conducted with and without the application of mechanical lumbar support. The lumbar support depth was mechanically adjusted to a $4 \mathrm{~cm}$ horizontal shell deflection (De Carvalho and Callaghan, 2015), which was defined as the anterior-posterior distance from the base of the mechanical support to the peak of the prominence apex (Figure 2). A $4 \mathrm{~cm}$ shell deflection was selected because of its documented ability to influence lumbar spine postures while driving (De Carvalho and Callaghan, 2012). The mechanical support was located inside the seatback, and when applied, caused the lower portion of the seatback to protrude anteriorly to support the lordosis curvature of the lumbar spine (De Carvalho and Callaghan, 2012). The apex of the lumbar support prominence was vertically aligned with the marked $\mathrm{L}_{3}$ spinal level (i.e., mid-point of the lumbar spine region). This alignment permitted consistency of support application between participants. The mechanical support used in this study is a commercially available model that is widely used in modern automotive seating (driver's seat only).

Figure 1 The sled-track unit. The impact was facilitated by the sled platform accelerating rearward under gravity and striking four springs mounted in parallel to the track base

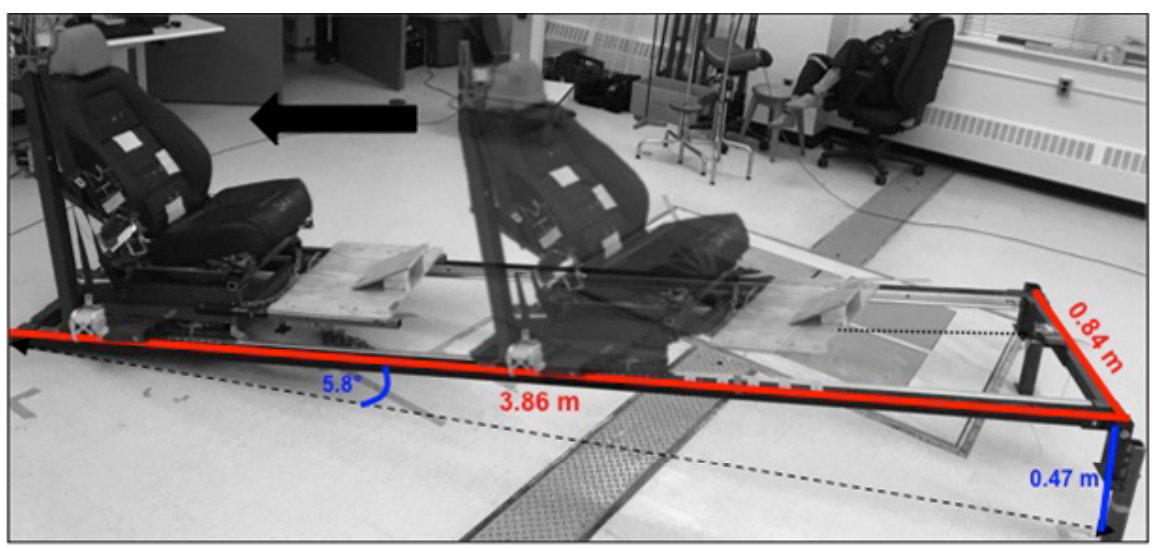

Figure 2 An image of the mechanical lumbar support installed inside the automotive seatback from a posterior perspective

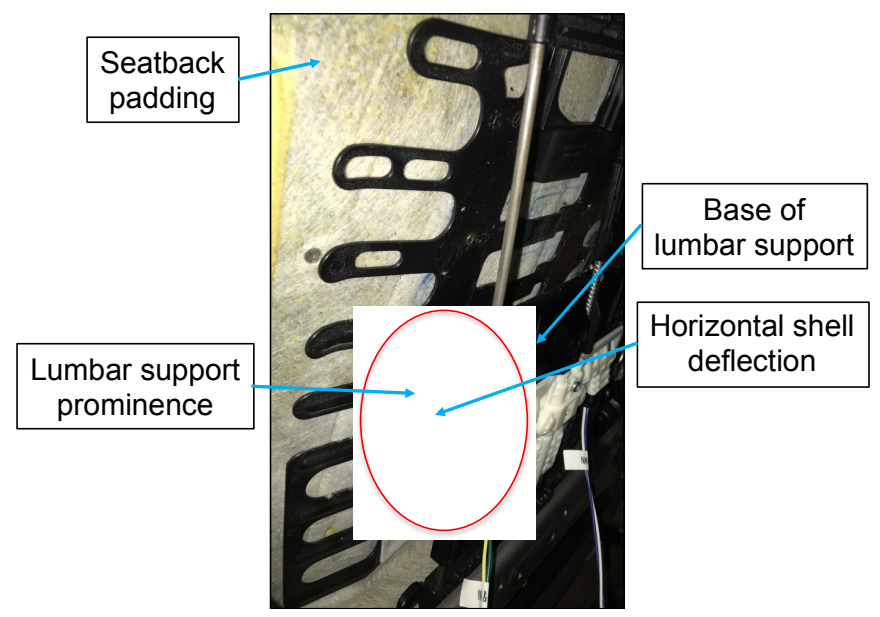




\subsection{Data acquisition}

Acceleration was measured with a triaxial accelerometer (377, ADXL, Analog Devices, Norwood, MA) that was mounted to the seating platform base and sampled at $5000 \mathrm{~Hz}$.

A ferroresistive pressure-measurement system (Version 3150, Tekscan Inc., Boston, MA, USA) was employed to monitor time-varying changes in seatback pressure. The pressure mat had a sensing area of $36.8 \mathrm{~cm}$ by $43.5 \mathrm{~cm}$ totalling 2288 sensing elements at a spatial resolution of 1.4 sensels per $\mathrm{cm}^{2}$. Prior to data collection, the mat was equilibrated via the application of uniform pressures across the entire sensing surface, followed by two-point power calibration. The pressure mat deformed to the contour of the seatback and was affixed using double-sided tape such that the inferior edge of the sensing area was positioned at the interface between the seatback and the seat pan (Figure 3). Pressure measurements were recorded via F-Scan Research 7.01 software (Tekscan Inc., Boston, MA, USA) at $500 \mathrm{~Hz}$ and this system was temporally synchronised with occupant kinematic data through a custom external trigger that was connected to the Optotrak ${ }^{\circledR}$ Data Acquisition Unit (Northern Digital Inc., Waterloo, ON).

Figure 3 A schematic of the pressure sensing system where (X, Y) represent the sensel number with respect to corner $1(\mathrm{C} 1)$ (left). Positioning of the pressure mat on the seatback, quantification of row offset (L), and digitised points (P1-5) (centre). Derivation of centre-of-force coordinates with respect to the mat local coordinate system (right)

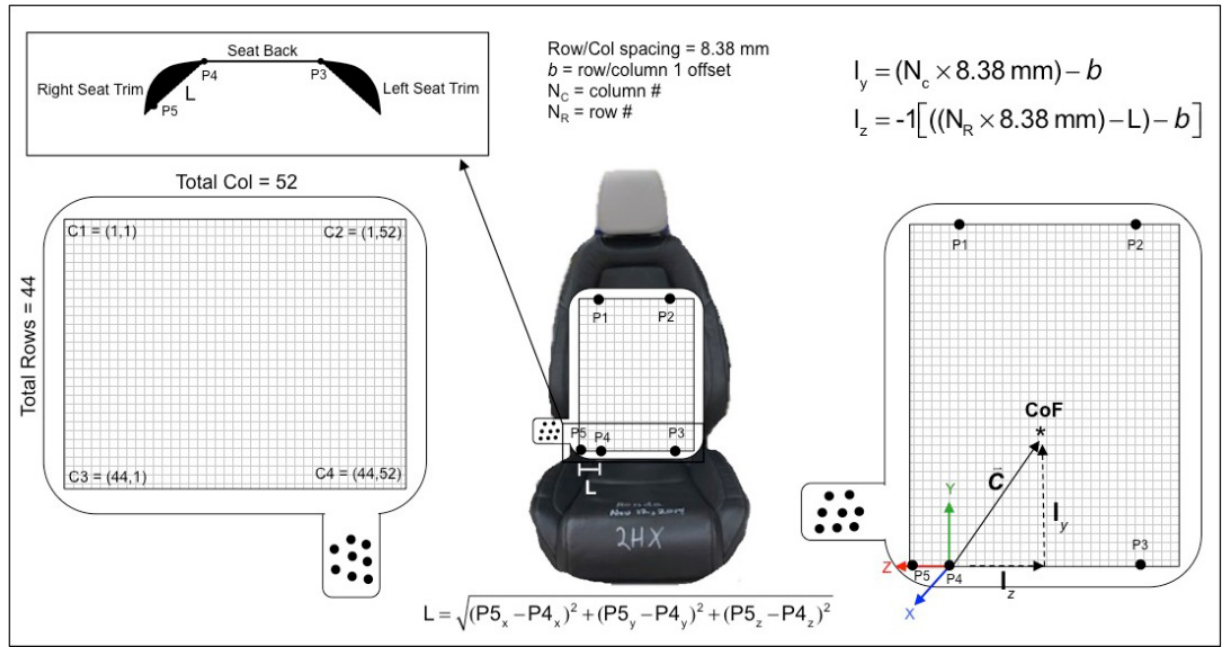

Rigid bodies with four active infrared markers (Northern Digital Inc., Waterloo, ON, Canada) were fastened to the lateral aspect of the left thigh (to track three-dimensional pelvis location) and to the sled platform. The boundaries of the pressure sensing area were digitised in the absence of the seated occupant (Figure 3) and, once seated, the bilateral position of the iliac crests and greater trochanters were digitised while the participant assumed an erect trunk position while facing forward in the automobile seat. These digitised landmarks were used to define the position of the pressure mat and the pelvis segment. Local coordinate systems (LCS) were reconstructed based on the transformations between rigid-body and pelvis-/mat-fixed coordinate systems. Position data were recorded using an Optotrak ${ }^{\circledR}$ motion capture system (Northern Digital Inc., Waterloo, ON, Canada) that sampled at a rate of $100 \mathrm{~Hz}$ while the simulated collisions 
were conducted within a calibrated measurement space. All data acquisition systems were centrally controlled using NDI First Principles software (Northern Digital Inc., Waterloo, ON, Canada).

\subsection{Data processing}

Raw position and pressure data were processed with custom code developed in MATLAB (version R2017a, Math Works, Natick, MA, USA). Acceleration data were filtered using SAE Channel Frequency Class (CFC) 60 (Society of Automotive Engineers, 1995). Peak acceleration was identified as the maximum acceleration quantity and the resultant velocity change was derived via trapezoidal integration of the acceleration-time series.

The total pressure was computed as the sum of the calibrated outputs from each sensel of the pressure mat. The total pressure quantity was multiplied by the sensel area $\left(7.02 \times 10^{-5} \mathrm{~m}^{2}\right)$ to determine the seatback force recorded from the entire sensing surface. The global maximum of the force-time history was then used to identify the moment of peak loading on the participant's body. The instant that the participant experienced the peak seatback force was examined because this instant in time is most likely to correspond to the occurrence of the highest low back injury potential. This decision was based on the fundamental rationale that injuries to lumbar spine tissues are caused by forces that facilitate subsequent physiological and structural (mal)adaptions. Of the three documented phases of occupant motion during a rear impact MVC (McConell et al., 1993), this analysis was limited to the initial rearward motion of the occupant into the seatback. At the identified frame, the region of force concentration was manually determined for derivation of area and centre-of-force $(\mathrm{CoF})$ variables. The employed masking approach was considered to be a conservative method used to eliminate noise due to mat crinkling and/or bending and permitted analyses of localised seat-occupant contact points (Kingston and Acker, 2018). The total force (as described above) and the area of the masked polygon (used to represent contact between the occupant's back and the seat back) were determined at the instant of peak seatback force together with the horizontal and vertical distance of the CoF with respect to corner 4 (C4) of the pressuresensing mat (Figure 3).

The CoF location was first determined with respect to the mat LCS. The horizontal component was determined by subtracting the distance between points 4 and 5 (Figure 3 ) from the horizontal distance of the $\mathrm{CoF}$ from corner $4\left(l_{z}\right)$, while the vertical component was determined as the vertical distance of the CoF from corner $4\left(l_{y}\right)$. The anteroposterior component $\left(l_{x}\right)$ in the mat system was assumed to be on the plane created by the digitised mat landmarks and thus was assigned a value of zero. These CoF coordinates were then transformed to the pelvis LCS for determination of vertical and lateral distance from the $L_{4}$ spinal level. The $L_{4}$ spinal level was selected given that electromyography-assisted models of the lumbar spine typically aim to calculate joint contact forces experienced at the $L_{4}-L_{5}$ spinal joint. Given that the iliac crest is the approximate level of the $L_{4}$ spinous process, the time-varying position of the $L_{4}-L_{5}$ joint with respect to the pelvis was approximated as the mid-point between the left and right iliac crest surface landmarks. In addition, the digitised points overlying the right and left iliac crest were used to quantify the waist width of each participant, defined as the horizontal medial-lateral distance between these two palpated landmarks. It should be noted that this method could be used 
to represent the CoF position with respect to any spinal level provided that the position is tracked with respect to the pelvis coordinate system.

Based on the measured seatback pressure, five dependent variables were quantified to characterise the seat-occupant interface. Total force was defined as the maximum force applied to occupant. This force magnitude was then normalised to participant-specific body mass (multiplied by the force of gravity) to obtain a measure of normalised seatback force. The area of the masked polygon depicting contact between the seatback and the occupant's back was quantified as the area of force concentration. Lastly, the distance of the CoF from the digitised landmark overlying the $L_{4}$ spinous process in the vertical (superior-inferior) and horizontal (medial-lateral) directions was taken as the CoF distances.

\subsection{Statistical analyses}

Parametric assumptions of normality and homogeneity of variance (between-participant tests only) were confirmed for each set of data based on the results of the Shirpo-Wilks and Levene's tests, respectively $(p>0.05)$. Mean differences in total force magnitude, area of force concentration, and horizontal and vertical distance of the CoF with respect to the approximated $L_{4}$ spinal level were assessed with separate, two-factor repeated measures analysis of variance (ANOVA) tests. One within-participant factor (support type) and one between-participant factor (biological sex) were used. If statistically significant interaction effects were detected, Tukey's post hoc analyses were implemented. For all statistical tests, $\alpha=0.05$ and the effect sizes for statistically significant mean differences were determined with standard Cohen's $d$ formulation. A strong effect was defined as $d>0.8$. RStudio version 1.0.136 with $\mathrm{R}$ version 3.4.1 (RStudio Inc., Boston, MA, USA) was used to conduct all statistical analyses.

\section{Results}

Of the 22 participants, 2 ( 1 male and 1 female) were eliminated from the statistical analyses due to marker occlusion and/or failure of the pressure mat to trigger during collision testing.

The mean differences in $\Delta \mathrm{V}(p=0.060)$ and peak acceleration $(p=0.826)$ were not statistically significant between simulated collisions with and without lumbar support. The average $\Delta \mathrm{V}$ and peak acceleration were $7.66 \mathrm{~km} / \mathrm{h}$ and $4.75 \mathrm{~g}$, respectively. These data confirm that impact parameters were similar for all laboratory-simulated rear impact collisions.

There were no significant interactions $(p=0.445)$ or main effects $(p>0.197)$ found for the total seatback force magnitude (Figure 4). The average seatback force was $820.5 \mathrm{~N}$ and $818.7 \mathrm{~N}$ during collisions with and without lumbar support, respectively. When normalised to body mass, seatback force was, on average, equivalent to participant-specific body mass in men and in women.

A significant support $\times$ sex interaction effect was detected for area of force concentration $(p=0.023)$ (Figure 4). Lumbar support use facilitated a significant decrease in the area of force concentration in men $(p<0.001, d=0.84)$ and women $(p=0.019, d=0.79)$ by a magnitude of $221.3 \mathrm{~cm}^{2}$ and $100.1 \mathrm{~cm}^{2}$, respectively (Figure 5). Although the force concentration area was similar between men and women 
during simulated collisions with lumbar support $(p=0.898)$, the area by which the seatback force was applied to the occupant's back was significantly greater for men than women without lumbar support ( $p=0.028, d=0.64)$.

Figure 4 Bar plots representing the mean of the respective dependent variable for men (white) and women (grey) during simulated rear impact collisions with and without lumbar support. Where applicable statistical significance is indicated $(p<0.05)$ and error bars represent one standard deviation
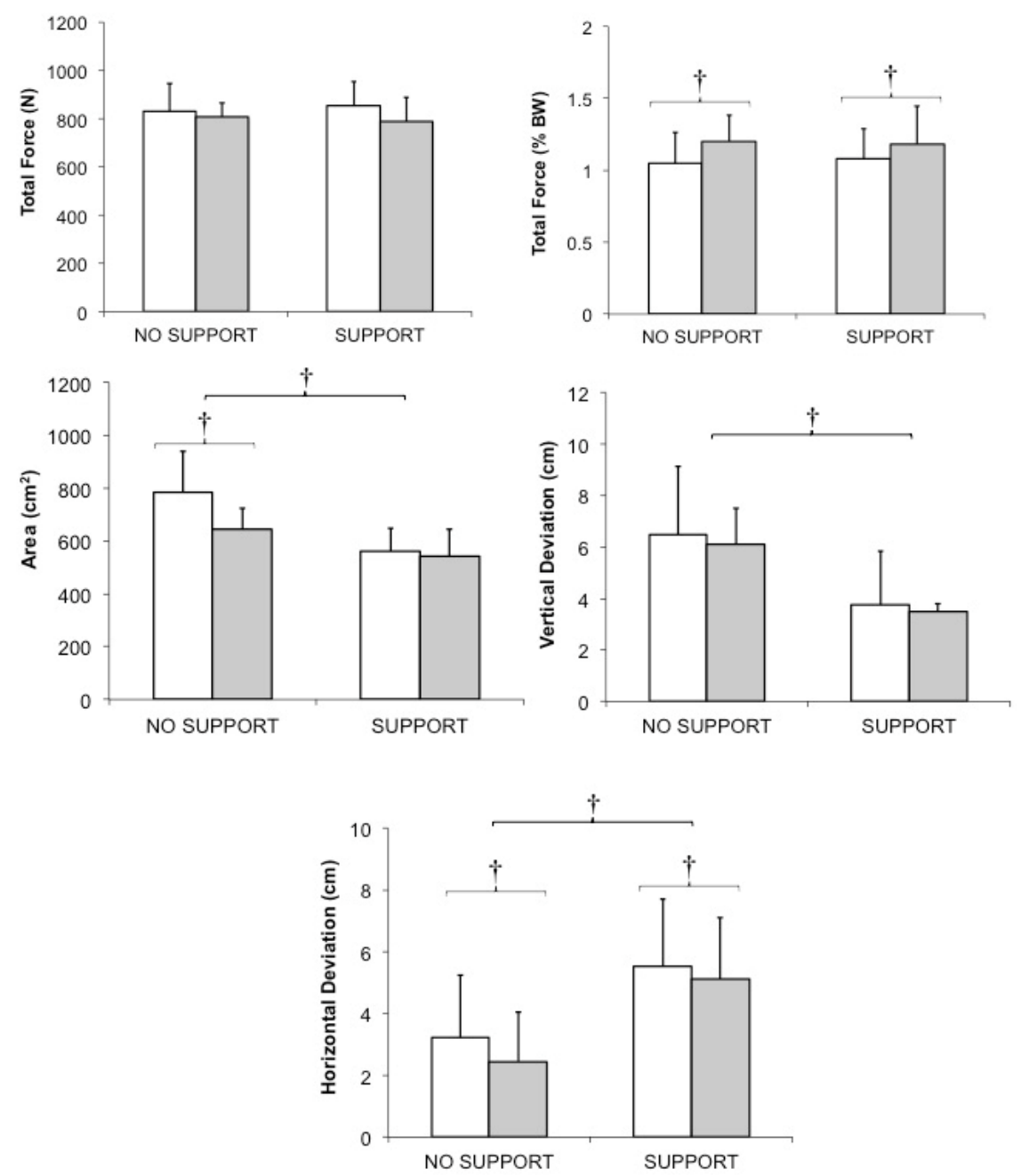

The vertical distance of the CoF from the $L_{4}$ spinous process was significantly different between lumbar support conditions $(p=0.002)$. In contrast, the differences in horizontal distance of the CoF with respect to the $L_{4}$ spinous process between support types was dependant on sex $(p=0.008)$ (Figure 4). The CoF location with respect to the $L_{4}$ spinal level had a greater cranial distance by $2.7 \mathrm{~cm}$ without lumbar support compared to when lumbar support was applied. The horizontal medial-lateral CoF distance was significantly 
greater in men than women with $(p=0.041, d=0.81)$ and without lumbar support $(p=0.039, d=0.86)$ by a magnitude of $3.9 \mathrm{~cm}$ and $7.8 \mathrm{~cm}$, respectively.

Figure 5 Typical seatback pressure output at the moment of impact during a rear end collision with and without the application of lumbar support

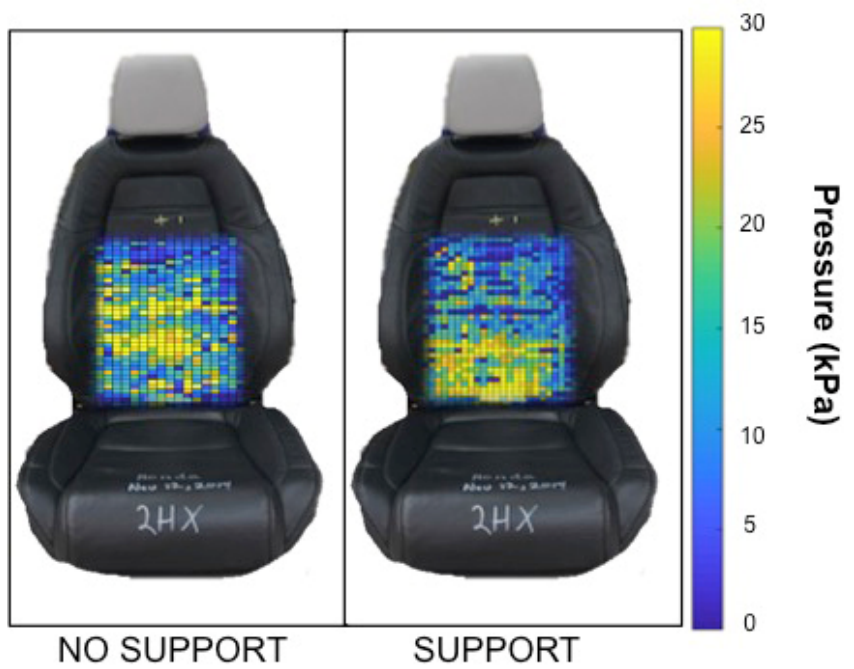

\section{Discussion}

This investigation was designed to examine the influence of lumbar support on characteristics of the seat-occupant interface during low-velocity rear impact MVCs. Characteristics of the seatback force (i.e., total force, area of force concentration, and $\mathrm{CoF}$ ) were derived based on high-resolution measurements of seatback pressure, which is a novel methodological approach for in vivo rear impact collision testing. Though the magnitude of lumbar support deflection is largely selected based on personal comfort (De Carvalho and Callaghan, 2015), the seat support dimensions examined in this study were selected as the boundary deflection conditions and included no lumbar support and a $4 \mathrm{~cm}$ lumbar support prominence. Analyses of the seatback force characteristics revealed that the application of lumbar support altered the point of force application together with the area of force concentration. However, the total seatback force magnitudes were similar, regardless of the seatback contour when exposed to the same rear impact collision severity.

The total seatback force estimates in the current investigation were considerably less $(\approx 680 \mathrm{~N})$ than in vivo estimates based on seatback deformation (Lawrence and Siegmund, 2000). One potential explanation for this discrepancy is rooted in differing methodological approaches of force derivation. Indeed, the employed masking approach used to eliminate perimeter pressure outputs that were suspected to be unrepresentative of seat-occupant contact (i.e., due to mat crinkling and bending) may have marginally reduced total force estimates, despite the established inter-researcher consistency of this technique (Kingston and Acker, 2018). Further, the differences in total seatback reaction force for a similar collision severity may, in part, differ due to several factors beyond the 
scope of this study, including: material properties of the tested automobile seat (e.g., leather vs. cloth exterior, density of cushioning, viscoelastic properties of seatback cushion, etc.) and vehicle make and model. It is also unknown if all seatback deformation in previous studies was due to seat-occupant contact or if it was a result of residual deformation towards the perimeter of the seatback (i.e., where potentiometers were affixed) (Lawrence and Siegmund, 2000). In contrast, seat-occupant contact was isolated to a greater extent in the current study, which permitted quantification of seatback reaction force specifically applied to the occupant.

Considering the observed differences in contact area without a change in force magnitude, a metric of stress may more accurately characterise the force and localised loading responses. Stress-based measures of applied loads to bone tissue have been gaining traction for the assessment of vertebral fracture risk (Duan et al., 2006, Travert et al., 2011, Nabhani and Wake, 2002, Anderson and Bouxsein, 2013). Recent findings reported by Zehr et al. (2019) further support a stress-based approach given that the external load applied exclusively to the lumbar spine was $195 \mathrm{~N}$ greater when lowvelocity MVCs were simulated with the application of lumbar support. When the seatback force was partitioned amongst the lumbar spine motion segments, there was a notable increase in seatback force applied at the $L_{3}-L_{4}$ and $L_{4}-L_{5}$ spinal levels (Zehr et al., 2019). A potential benefit of a stress-based or localised loading measures is that they may glean reasonable insight into the internal joint loading response. This conclusion is based on the strong biomechanical notion that internal spinal joint loading is a result of external (i.e., seatback force) and muscular forces. Recent assessments of muscle activation revealed that trunk muscles (i.e., lumbar erector spinae, thoracic erector spinae, and rectus abdominus) are not recruited beyond $15 \%$ of the maximum voluntary isometric contraction during un-anticipated low-velocity rear-impact collisions (Fewster et al., 2019). The internal loading resulting from this low-level muscle activation is expected to be marginal, leaving the joint contact force to be predominately driven by external loads. Given the focal force distribution observed in this study together with increased external loading applied to each spinal joint (Zehr et al., 2019), it is conceivable that the lumbar spine is exposed to greater internal shear force magnitudes with lumbar support compared to without, but there is evidence to suggest that the lumbar spine may be in a better position to tolerate that force (i.e., in a less flexed posture) (De Carvalho and Callaghan, 2012, 2015).

Based on the observed vertical distance from the $L_{4}$ spinal level, the CoF location corresponds to the upper lumbar region $\left(\approx L_{1}\right)$ without lumbar support and the mid-lumbar region $\left(\approx L_{3}\right)$ when lumbar support is applied. A greater CoF horizontal distance from the parasagittal plane was observed when lumbar support was applied, with this distance being greater in men than women for both seat support conditions. Considering the seatback width of $30 \mathrm{~cm}$, differences in horizontal CoF distance could be attributed to sex-based anthropometrics. On average, men within the tested sample had a waist width that was over $3 \mathrm{~cm}$ greater than the seatback width. As such, the presence of bilateral seat bolsters coupled with a narrow seatback dimension may have compromised the ability of all but one male participant to sit symmetrically within the automobile seat (i.e., with their back flush against the seatback). An elevated horizontal CoF distance conceivably resulting from this design feature and exacerbated by the use of lumbar support has potential to induce off-axis moments in the lumbar spine at the moment of impact, particularly axial twist. 
Before interpreting and implementing the findings from this study, the following limitations should be considered. First, pressure-sensing units are limited to measuring forces acting normal to the seatback (i.e., normal to $27^{\circ}$ seat recline angle). As such, the implementation of this method may be sensitive to seat recline angle. This recommendation is due the unidirectional nature of the transducer together with the strong likelihood of appreciable vertical force components in more reclined positions. Second, the seatback-occupant interface was characterised on one automotive seat model (i.e., 2017 Honda CRV model) with specific characteristics of the automotive seat (i.e., angle of recline) that were further standardised across all simulated collisions. It is acknowledged that different seat designs may alter how individuals position themselves in the seat. Most notably, it could be expected that automotive seating with altered lumbar support and bolster dimensions could influence how the seatback force in transmitted to the occupant's back. Although the aforementioned design constraints afforded greater control over the potential confounding effects of a self-selected seat configuration on characteristics of the seat-occupant interact, these findings are only generalisable to automotive seats with similar dimensions. Third, a single simulated crash severity was examined in this study (i.e., $\Delta V=7.66 \mathrm{~km} / \mathrm{h}$ ), albeit this severity is at the higher-end of simulated rear-impact collision performed with human volunteers. Of the seat-occupant parameters examined, total seat back force would be expected to decrease; however, there is no reason to believe that $\mathrm{CoF}$ and contact area would differ during less severe laboratory-simulated rear-impact collisions under the same seat characteristics. Lastly, although the inclusion criteria for recruitment purposes included a large anthropometric range (10th-90th), participants from this study had a stature that was within the 25th to 75th percentiles and an average BMI that represents a healthy population. As such, the seat-occupant interactions that are seemingly driven by body dimensions (i.e., CoF distance) may be exacerbated for individuals beyond the examined height and BMI ranges.

\section{Conclusions}

Lumbar support alters characteristics of the seat-occupant interaction during low-velocity rear impact MVCs. Specifically, significant effects were found with respect to how and where the seatback reaction force was applied to the occupant. For this reason, stressrelated measures should be implemented for the examination of injury potential following low-velocity rear impact collisions. To minimise the medial-lateral CoF distance from the parasagittal plane, automobile seating should be designed with a seatback width that is large enough to accommodate torso anthropometrics of a larger population percentage to permit symmetrical positioning against the seatback.

\section{References}

Anderson, D.E. and Bouxsein, M.L. (2013) 'Factor of risk for fracture', Stud Mechanobiol Tissue Eng Biomater, Vol. 5, pp.133-150.

Arbogast, K.B., Mathews, E.A., Seacrist, T., Maltese, M.R., Hammond, R., Balasubramanian, S., Kent, R.W., Tanji, H.S.S.L. and Higuchi, K. (2012) 'The effect of pretensioning and age on torso rollout in restrained human volunteers in far-side lateral and oblique loading', Stapp Car Crash Journal, Vol. 56, pp.443-467. 
Bancej, C., Jayabalasingham, B., Rao, D.P., Groh, M. and Jayaraman, G.C. (2015) 'Trends and projections of obesity among canadians', Health Promotion and Chronic Disease Prevention in Canada, Vol. 35, pp.109-112.

Barrett, J.M., Fewster, K.M., Gooyers, C.E., Parkinson, R.J. and Callaghan, J.P. (2018) 'Modelaided design of a rear-vehicle impact testing system for in-vivo investigations', 14th Annual Injury Biomechanics Symposium, Columbus, $\mathrm{OH}$.

Berglund, A., Alfredsson, L., Jensen, I., Cassidy, J.D. and Nygren, A. (2001) 'The association between exposure to a rear-collision and future health complaints', Journal of Clinical Epidemiology, Vol. 54, pp.851-856.

Brison, R.J., Hartling, L. and Pickett, W. (2000) 'A prospective study of acceleration-extension injuries following rear-end motor vehicle collisions', Journal of Musculoskeletal Pain, Vol. 8, pp.97-113.

Cavanaugh, J.M., Lu, Y., Chen, C. and Kallakuri, S. (2006) 'Pain generation in lumbar and cervical facet joints', The Journal of Bone and Joint Surgery, Vol. 88, pp.63-67.

Chen, J.C., Dennerlein, J.T., Chang, C.C., Chang, W.R. and Christiani, D.C. (2005) 'Seat inclination, use of a lumbar support and low back pain of taxi drivers', Scand J. Work Environ Health, Vol. 31, pp.258-265.

DE Carvalho, D.E. and Callaghan, J.P. (2012) 'Influence of automobile seat lumbar support prominence on spine and pelvic postures: a radiological investigation', Applied Ergonomics, Vol. 43, pp.876-882.

De Carvalho, D.E. and Callaghan, J.P. (2015) 'Spine posture and discomfort during prolonged simulated driving with self-selected lumbar support prominence', Human Factors: The Journal of the Human Factors and Ergonomics Society, Vol. 57, pp.976-987.

Donnelly, C.J., Callaghan, J.P. and Durkin, J.L. (2009) 'The effect of an active lumbar system on the seating comfort of officers in police fleet vehicles', International Journal of Occupational Safety and Ergonomics, Vol. 15, pp.295-307.

Drake, J.D.M., Aultman, C.D., Mcgill, S.M. and Callaghan, J.P. (2005) 'The influence of static axial torque in combined loading on intervertebral joint failure mechanics using a porcine model', Clinical Biomechanics, Vol. 20, pp.1038-1045.

Duan, Y., Duboeuf, F., Munoz, F., Delmas, P.D. and Seeman, E. (2006) 'The fracture of risk index and bone mineral density as predictors of vertebral structural failure', Osteoporos Int, Vol. 17, pp.54-60.

Fast, A., Sosner, J., Begeman, P., Thomas, T.A. and Chiu, T. (2002) 'Lumbar spinal strains associated with whiplash injury: a cadaveric study', American Journal of Physical Medicine and Rehabilitation, Vol. 81, pp.645-650.

Fewster, K.M., Viggiani, D., Gooyers, C.E., Parkinson, R.J. and Callaghan, J.P. (2019) 'Characterizing trunk muscle activations during simulated low-speed rear impact collisions', Traffic Injury Prevention, Vol. 20, pp.314-319.

Flegal, K.M., Kruszon-Moran, D., Carroll, M.D., Fryar, C.D. and Ogden, C.L. (2016) 'Trends in obesity among adults in the United States, 2005 to 2014', Journal of the American Medical Association, Vol. 315, pp.2284-2291.

Gallagher, S., Marras, W., Litsky, A.S. and Burr, D. (2005) 'Torso flexion loads and the fatigue failure of human lumbosacral motion segments', Spine, Vol. 30, pp.2265-2273.

Gates, D., Bridges, A., Welch, T.D.J., Lam, T., Scher, I. and Yamaguchi, G. (2010) 'Lumbar loads in low to moderate speed rear impacts', SAE World Congress and Exhibition, Detriot, MI.

Gushue, D.L., Probust, B.W., Benda, B., Joganich, T., Mcdonough, D. and Markusewski, M.L. (2006) 'Effects of velocity and occupant sitting position on kinematics and kinetics of the lumbar spine during simulated low-speed rear impacts', ASSE Professional Development Conference and Exposition, Seattle, American Society for Engineers, Washington. 
Hales, C.M., Fryar, C.D., Carroll, M.D., Freedman, D.S., Aoki, Y. and Ogden, C.L. (2018) 'Differences in obesity prevalence by demographic characteristics and urbanization level among adults in the United States, 2013-2016', Journal of the American Medical Association, p.319.

Howarth, S.J. and Callaghan, J.P. (2012) 'Compressive force magnitude and intervertebral joint flexion/extension angle influence shear failure force magnitude in the porcine cervical spine', Journal of Biomechanics, Vol. 45, pp.484-490.

Kaneoka, K., Ono, K., Inami, S. and Hayashi, K. (1999) 'Motion analysis of cervical vertebrae during whiplash loading', Spine, Vol. 24, pp.763-770.

Kingston, D.C. and Acker, S.M. (2018) 'Thigh-calf contact parameters for six high knee flexion postures: onset, maximum angle, total force, contact area, and center of force', Journal of Biomechanics, Vol. 67, pp.46-54.

Lawrence, J.M. and Siegmund, G.P. (2000) 'Seat back and head restraint response during low-speed rear-end automobile collisions', Accident Analysis and Prevention, Vol. 32, pp.219-232.

Mcconell, W.E., Howard, R.P., Guzman, H.M., Bomar, J.B., Raddin, J.H., Benedict, J.V., Smith, H.L. and HATSELL, C.P. (1993) Analysis of Human Test Subject Kinematic Responses to Low Velocity Rear End Impacts, The Engineering Society For Advancing Mobility Land Sea Air and Space Technical Paper Series.

Mcgill, S.M. and Norman, R.W. (1986) 'Partitioning of the L4-15 dynamic moment into disc, ligamentous, and muscular components during lifting', Spine, Vol. 11, pp.666-678.

Nabhani, F. and Wake, M. (2002) 'Computer modelling and stress analysis of the lumbar spine', Journal of Materials Processing Technology, Vol. 127, pp.40-47.

Seifert, J. (2007) 'Incidence and ecnomic burden of injuries in the United States', Journal of Epidemiology and Community Health, Vol. 61, pp.926-927.

Siegmund, G.P., Brault, J.R. and Wheeler, J.B. (2000) 'The relationship between clinical and kinematic responses from human subject testing in rear-end automobile collisions', Accident Analysis and Prevention, Vol. 32, pp.207-217.

Siegmund, G.P., Heinrichs, B.E., Lawrence, J.M. and Philippens, M.M. (2001) 'Kinetic and kinematic responses of the RID2a, hybrid III and human volunteers in low-speed rear-end collisions', Stapp Car Crash Journal, Vol. 45, pp.239-56.

Travert, C., Jolivet, E., Sapin-DE Brossess, E., Mitton, D. and Skalli, W. (2011) 'Sensitivity of patient-specific vertebral finite element model from low dose imaging to material properties and loading conditions', Medical and Biological Engineering and Computing, Vol. 49, pp.1335-1361.

Van Dieën, J.H. and D.E., Looze, M.P. (1999) 'Sensitivity of single-equivalent trunk extensor muscle models to anatomical and functional assumptions', Journal of Biomechanics, Vol. 32, pp.195-198.

Winter, D.A. (2009) Biomechanics and Motor Control of Human Movement, 4th ed., Hoboken, N.J., John Wiley and Sons, Inc.

Yingling, V.R. and Mcgill, S.M. (1999) 'Anterior shear of spinal motion segments: kinematics, kineatics, and resultant injuries observed in a porcine model', Spine, Vol. 24, pp.1882-1889.

Zehr, J.D., Fewster, K.M., Gooyers, C.E., Parkinson, R.J. and Callaghan, J.P. (2019) 'Partitioning the total seatback reaction force amongst the lumbar spine motion segments during simulated rear-impact collisions', International Journal of Occupational Safety and Ergonomics, Vol. 7, pp.1-7. 